\title{
Treatment of pulmonary arterial hypertension in children
}

\author{
Matthias Gorenflo, Victoria C. Ziesenitz \\ Department of Pediatric Cardiology and Congenital Heart Diseases, Centre of Child and Adolescent Health, University Hospital Heidelberg, \\ Heidelberg, Germany \\ Contributions: (I) Conception and design: Both authors; (II) Administrative support: Both authors; (III) Provision of study materials or patients: None; \\ (IV) Collection and assembly of data: Both authors; (V) Data analysis and interpretation: Both authors; (VI) Manuscript writing: Both authors; (VII) \\ Final approval of manuscript: Both authors. \\ Correspondence to: Matthias Gorenflo, MD. Department of Pediatric Cardiology and Congenital Heart Diseases, Centre of Child and Adolescent \\ Health, University Hospital Heidelberg, Im Neuenheimer Feld 430, D-69120 Heidelberg, Germany. \\ Email: Matthias.Gorenflo@med.uni-heidelberg.de.
}

\begin{abstract}
Pulmonary arterial hypertension $(\mathrm{PAH})$ is a devastating illness causing already significant morbidity in childhood. Currently approved treatment options for children comprise the endothelin receptor antagonist bosentan, as well as the phosphodiesterase-5 inhibitor sildenafil. But PAH treatment has advanced significantly over the past decade, and new classes of targeted drug therapies, such as stimulators of the soluble guanylate cyclase (riociguat) or prostacyclin receptor agonists (selexipag), are currently evaluated regarding their efficacy and safety in children, in order to limit off-label use. Due to the different etiologies in children, such as PAHCHD, there is no evidence that initial combination therapy in children is superior to a mono-therapy with respect to survival. Special attention should also be paid to the pharmacology of PAH drugs in children, which might be impacted by ontogeny or drug-drug-interactions. Therapeutic drug monitoring may be useful in pediatric patients. There is a clear need for more controlled studies of PAH medications, alone or in combination therapy in the pediatric age group. Data from clinical trials as well as from patient registries should be pooled to optimize drug development and evaluation, trial design, and evidence-based pharmacotherapy in pediatric patients with $\mathrm{PAH}$. In this review, the current treatment options of pediatric $\mathrm{PAH}$ are summarized, and an overview of new treatment concepts, which are already evaluated in adults, is presented.
\end{abstract}

Keywords: Pulmonary arterial hypertension (PAH); pulmonary hypertension; endothelin receptor antagonists; phosphodiesterase 5 inhibitors; congenital heart disease (CHD)

Submitted Nov 05, 2020. Accepted for publication Apr 27, 2021.

doi: $10.21037 / \mathrm{cdt}-20-912$

View this article at: http://dx.doi.org/10.21037/cdt-20-912

\section{Introduction}

Pulmonary arterial hypertension (PAH) is a devastating illness with significant morbidity and decreased life expectancy, already in childhood. PAH may have different etiologies, of which PAH due to congenital heart defects (PAH-CHD) and idiopathic PAH may be the two most frequently underlying causes for PAH in children. In PAHCHD, the disease is most often associated with left-toright shunt due to congenital heart disease leading to a poor prognosis with early death due to right ventricular failure (1). A national epidemiological study from the
Netherlands over a 15 -year period reported an annual incidence rate of 63.7 per million children with "transient" $\mathrm{PAH}$ being the most prevalent one (82\%, e.g., PAH-CHD after shunt defect repair or PPHN). Of the remaining patients, $42 \%$ had $\mathrm{PH}$ due to lung disease, $27 \%$ had $\mathrm{PH}$ due to left heart disease, $26 \%$ had "progressive" $\mathrm{PAH}$ (namely, IPAH and PAH-CHD), and less than one percent had CTEPH. Based on these Dutch data, the mean annual incidence and point prevalence for patients with idiopathic PAH were 0.7 and 4.4, and for patients with PAH-AHF 2.2 and 15.6 cases per million children, respectively (2). Children with PAH are currently treated according to 
therapeutic guidelines extrapolated from adults, but especially in children with $\mathrm{PAH}-\mathrm{CHD}$, their specific pathophysiology has to be taken into account (3).

New therapeutic targets and drug classes have evolved over the years, being adopted from adult into pediatric $\mathrm{PAH}$ treatment. Especially in the last two decades progress has been made with promising substances that promote pulmonary vasodilation and/or antiproliferative effects in the pulmonary vasculature.

We summarize the current therapeutic options and possible new therapeutic approaches for pediatric $\mathrm{PAH}$.

\section{Treatment algorithm}

Treatment of pediatric pulmonary hypertension is focused on two aspects: specific pulmonary antihypertensive treatment and conventional and supportive therapy (4). The pediatric guidelines have recently been updated by the Pediatric Task Force of the 6th World Symposium on Pulmonary Hypertension in 2018.

\section{Conventional and supportive therapy}

The conventional therapy of pediatric PAH includes diuretics, anticoagulation, digoxin.

Diuretics are often needed to relieve symptoms in patients with signs of right heart failure or in patients with pulmonary hypertension related to left ventricular diastolic dysfunction. Despite the fact that no randomized controlled trials have been conducted on the use of diuretics for the indication of pulmonary arterial hypertension, diuretics are frequently used for treatment of fluid overload which may present in children with hand, ankle or eyelid edema, hepatic congestion as ascites. In children, hydrochlorothiazide or furosemide may be used, sometimes combined with aldosterone antagonists such as spironolactone for their additive effect.

Diuretics however should be used with caution since they reduce preload. Reduction in preload in turn will reduce ventricular filling and thus cardiac output; that may lead to cardiocirculatory compromise if reduced below a critical level. In addition, side effects of potassium depletion associated with hydrochlorothiazide and furosemide will increase the risk for arrhythmia in patients treated with these substances.

Digoxin and digitoxin are not recommended for pediatric PAH on a routine basis. Historically they were recommended in patients with right ventricular dysfunction associated with PAH (5). The use of digoxin or digitoxin can be considered in individual patients presenting with overt right heart failure (4).

Anticoagulation with warfarin or phenprocoumon was once not recommended on a routine basis in children with idiopathic pulmonary arterial hypertension (6). Chronic anticoagulation can be useful in patients with progressive IPAH/HPAH (empirical goal INR 2.0 to 2.5), patients with CTEPH, patients with low cardiac output, and those with hypercoagulable states (7). The risks of bleeding complications (e.g., cerebral, gastrointestinal etc.) must be weighed against potential benefits in patients with low cardiac output. Often right heart failure will be associated with bleeding symptoms and/or anomalies in coagulation screening tests (6).

For pediatric patients, direct oral anticoagulants may pose a more suitable alternative since invasive therapeutic drug monitoring can be avoided, but there are not even adult data available whether these agents prove the same benefit as vitamin $\mathrm{K}$ antagonists (8). There are studies on the use of direct oral anticoagulants underway, but not in pediatric patients with pulmonary arterial hypertension (9), although these agents are used in practice for this indication. Pediatric data has only been established for the use of dabigatran in venous thromboembolism $(10,11)$. Nevertheless, there might be in vitro evidence pointing at pharmacokinetic drug interactions between direct oral anticoagulants and phosphodiesterase 5 -inhibitors (12).

Oxygen as supportive therapy is indicated in patients with proven hypoxemia during rest $(<92 \%)$ or during exercise. Oxygen may relieve symptoms in children with severe right heart failure due to PAH $(4,7,13)$.

\section{Specific pulmonary-antibypertensive treatment}

\section{Calcium channel blockers (CCBs)}

CCBs are indicated in patients with $\mathrm{PAH}$ who show a positive response in acute pulmonary vasoreactivity testing (AVT). For patients with IPAH/HPAH, the hemodynamic change that defines a positive response to AVT in $\mathrm{PH}$ without a cardiovascular shunt is a $\geq 20 \%$ fall in both mean PAP and PVR/SVR ratio without a decrease in cardiac index (7). The World Symposium on Pulmonary Hypertension 2018, however, has recommended the use of the Sitbon criteria for a positive AVT in children with IPAH/HPAH, as defined by a decrease in mean PAP by at least $10 \mathrm{mmHg}$ to a mPAP value below $40 \mathrm{mmHg}$ without a fall in cardiac output (14). Amlodipine, nifedipine and diltiazem are the CCBs that are used in most centers (for dosage recommendations, 
see Table 1). Children with increased right atrial pressures (>8 $\mathrm{mmHg}$ ), right ventricular systolic dysfunction and/ or overt heart failure should not be treated with CCBs. Verapamil should not be used due to its marked negative inotropic effects. Patients under monotherapy with $\mathrm{CCB}$ must be monitored as any other patient with iPAH since deterioration may occur over time (26).

\section{Targeted therapies}

In the last two decades progress has been made with promising substances that promote pulmonary vasodilation and/or antiproliferative effects in children with PAH. These therapies target the three main therapeutic avenues in $\mathrm{PAH}$ : (I) the nitric oxide pathway, (II) the endothelin pathway and (III) the prostacyclin pathway $(27,28)$.

\section{Phosphodiesterase 5 inhibitors}

Phosphodiesterase type 5 inhibitors, e.g., sildenafil and tadalafil, are used in children with PAH. Sildenafil usually is the drug preferably used by most centers for this indication. Studies suggest favorable effects of sildenafil in this population $(21,29)$. The clinical experience with sildenafil in children has recently been summarized by Dhariwal and Simonca (30,31). Most of the initial studies included patients with different etiologies of PAH.

Oral dosage recommendations vary: in children weighing $8-20 \mathrm{~kg}$ an oral dose of $10 \mathrm{mg}$ t.i.d. Sildenafil has been recommended, and for children $>20 \mathrm{~kg}$ a dose of $20 \mathrm{mg}$ t.i.d. has been recommended by the EMA (22). Other dosing practices include $0.5-2 \mathrm{mg} / \mathrm{kg} / \mathrm{d}$ divided in 3-4 doses $(0.125-0.5 \mathrm{mg} / \mathrm{kg}$ t.i.d./q.i.d.; Table 1). Sildenafil dosing in children has been limited to $20 \mathrm{mg}$ t.i.d. after the U.S. Food and Drug Administration (FDA) issued a warning regarding high doses of sildenafil based on the STARTS-2 trial (22). Data from a large cohort of 269 children $<18$ years proved safety and efficacy when sildenafil was administered at $1 \mathrm{mg} / \mathrm{kg}$ t.i.d. (32). In children $<2$ years of age weighing less than $8 \mathrm{~kg}$ sildenafil has been administered in dosages of $0.5-1.0 \mathrm{mg} / \mathrm{kg}$ BW t.i.d. which was increased to $1.5-8 \mathrm{mg} /$ $\mathrm{kg} / \mathrm{d}$ in 3-4 doses. It was tolerated at that dose in the setting of PAH associated with chronic lung disease (33).

After oral administration, sildenafil is rapidly absorbed over $0.5-1.5$ hours, and its bioavailability has been described with around $40 \%$ in adults. Maximum plasma concentrations are reached about $0.5-2.5 \mathrm{~h}$ after administration. Sildenafil is then rapidly metabolized by cytochrome $\mathrm{P} 450$ enzymes CYP3A4/5 (also CYP3A7 in neonates) and CYP2C9 to $\mathrm{N}$-desmethylsildenafil (UK-103320), which has about 50\% of the parent drug's activity.

The route of administration of sildenafil has an important influence on bioavailability: clinical data indicate suboptimal enteral absorption of this drug with $50 \%$ of treated children lacking exposure $(34,35)$. Sublingual administration has been shown to produce higher exposure and should be the route of choice in children (36).

Less data is available for the use of oral tadalafil in children, as for the transition from sildenafil to tadalafil. Tadalafil has a longer half-life and longer duration of action than sildenafil and it is also metabolized by CYP3A (37). The pharmacokinetics of tadalafil in children were first studied by Kohno et al. (38). Tadalafil was administered to 23 children aged between 0.25 and 17.4 years at an empirical daily dose of $0.97 \pm 0.41 \mathrm{mg} / \mathrm{kg}$. Clearance and volume of distribution were higher than reported in adults and no effect of age, concomitant treatment with bosentan, or the estimated glomerular filtration rate were noted. A more recent study reported lower exposure (AUC), Cmax and T1/2 in children, but Cmax was significantly higher during coadministration of bosentan and oral prostacyclin (39). A retrospective study in 33 pediatric patients concluded that tadalafil has been beneficial for transition from sildenafil with the potential advantage of a once-daily dosing (40). Takatsuki et al. investigated the safety, tolerability, and effects of tadalafil in children (aged 4-18 years) with pulmonary arterial hypertension $(\mathrm{PAH})$ after transition from sildenafil or with tadalafil as initial therapy. Clinical and hemodynamic improvement was reported for most patients in this study (40).

In another small multicentre study in 25 patients aged 2 months to 5 years with PAH-CHD or PPHN, hemodynamic improvement could be observed during tadalafil in patients who had been treated with sildenafil before or who were treatment-naïve (41).

Japanese post-marketing surveillance data was used to assess safety and effectiveness of tadalafil in patients $<18$ years (42). Among 391 patients included in the safety analysis, the overall incidence rate of ADRs was $16.6 \%$. Regarding effectiveness, the incidence of WHO functional class improvement at 3 months, 1 year, and 2 years after the initiation of tadalafil and last observation in pediatric patients were $16.5 \%, 19.7 \%$, and $16.3 \%$, respectively (42).

\section{Transient postoperative PAH}

Sildenafil is also available as an intravenous preparation and is used in children with congenital heart defects for transient postoperative PAH in the PICU in doses of $0.7-$ 


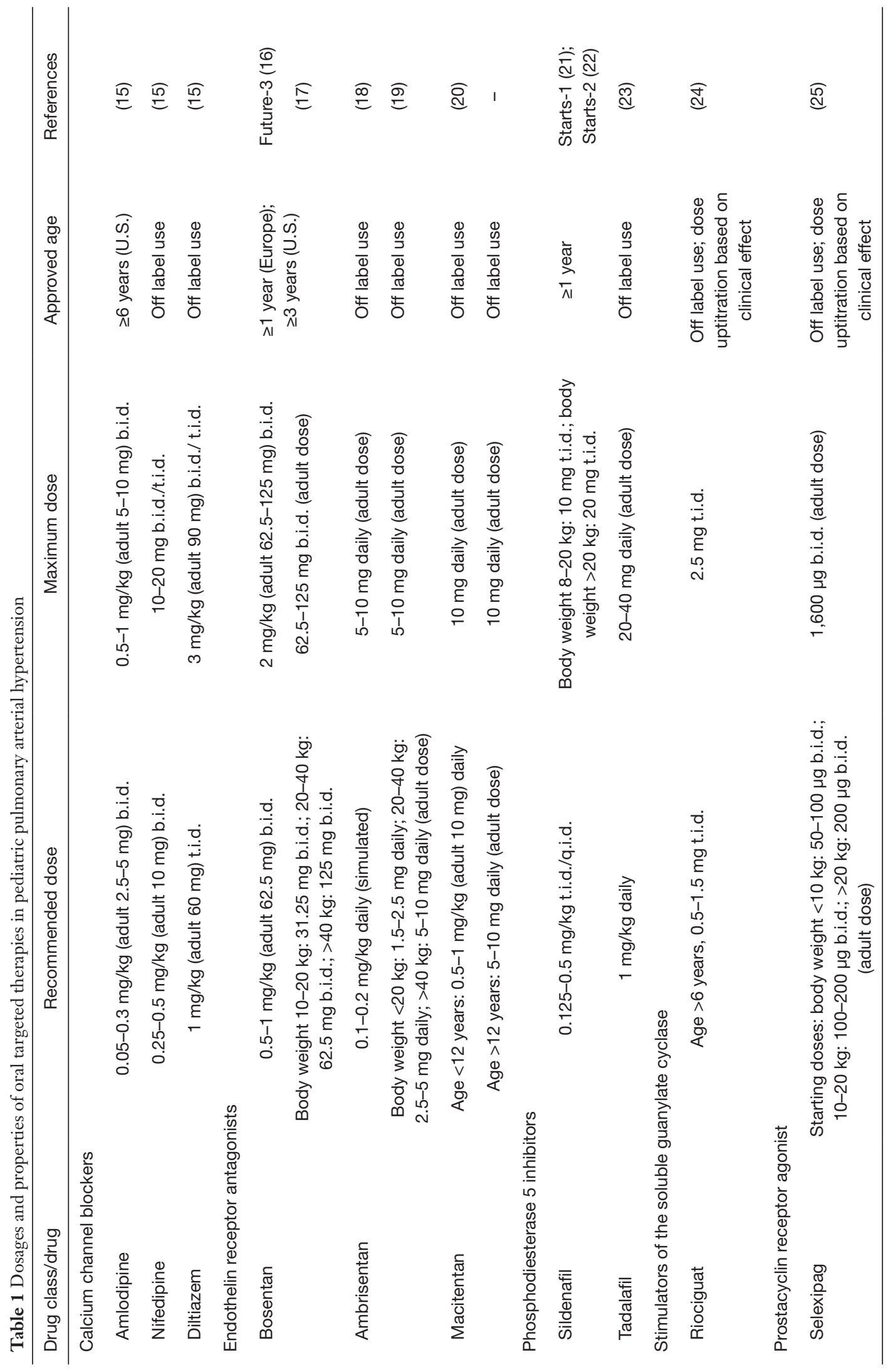


$2 \mathrm{mg} / \mathrm{kg} / \mathrm{d}$ during continuous monitoring of systemic blood and central venous pressure.

Tadalafil has also been used perioperatively in patients with PAH due to systemic-to-pulmonary shunts (43). In comparison with sildenafil, tadalafil was administered to 21 children before and after surgery. There was no difference between groups regarding hemodynamic (PA pressure, PA pressure/systemic pressure ratio) clinical (ICU length of stay) and safety parameters.

\section{Eisenmenger}

PDE5 inhibitors have also been established as pulmonary vasodilator therapy in patients with Eisenmenger syndrome. A recent systematic review reported an improvement of WHO functional class and exercise functions, while hemodynamic measurements did not show a significant improvement (44). Several small studies in young Eisenmenger patients (mean age approx. 30 years) reported improved quality of life and functional capacity during sildenafil treatment, and even increased survival during long-term treatment $(45,46)$. Similar results were reported for a small cohort of adolescent and young adult Eisenmenger patients (47).

Experience on the use of tadalafil in patients with Eisenmenger syndrome is scarce, but small studies report a benefit regarding 6-MWD, WHO FC and PVR in adult patients $(48,49)$. In a small prospective study, 18 patients with mostly $\mathrm{PAH}-\mathrm{CHD} \pm$ Eisenmenger syndrome aged 4-24 years were switched from sildenafil to tadalafil. A short-term follow-up 6 weeks later showed no statistically significant changes in NYHA class, but patients described a decrease in symptoms (chest pain, cyanosis, and exerciseinduced fatigue) compared to sildenafil, and the 6-MWD was significantly longer (23).

\section{Fontan circulation}

There is some evidence that PDE5 inhibitors have beneficial short-term and long-term effects in patients after Fontan surgery. Tunks et al. studied nine children $<10$ years undergoing routine cardiac catheterization after Fontan surgery. A single IV dose of sildenafil improved cardiopulmonary hemodynamics, increasing cardiac index (50). Similar results were reported by Mori et al., who studied 42 pediatric and adolescent patients with single ventricle physiology and reported a significant reduction in PVR and significantly improved 6MWD and NYHA functional class (51). Hager et al. reported an improved exercise capacity in Fontan patients even after a single dose of sildenafil (52). A recent systematic review suggested that sildenafil among bosentan and iloprost may increase exercise capacity in patients in Fontan patients (53)

Tadalafil has also been studied in patients with Fontan circulation (54). Sabri et al. report on their experience in 15 patients after modified Fontan operation who were treated with tadalafil for 6 weeks. Tadalafil was shown to have a beneficial effect on myocardial function, exercise performance, and improvement in NYHA functional class (54).

\section{Endothelin receptor antagonists}

Endothelin receptor antagonists are currently, besides phosphodiesterase 5 inhibitors, applied in the long-term therapy of pediatric PAH.

Bosentan, an orally administered dual endothelin receptor antagonist targeting the endothelin receptors type A (ETA) and type B (ETB), predominantly used as ERA in children and is approved by the EMA for children older than one year of age. Recommendation for dosage is $0.5-2 \mathrm{mg} / \mathrm{kg}$ BW b.i.d. (see Table 1). Adverse effects that are observed include nausea, headache, flushing, abdominal pain and edema. Regular liver function tests and blood counts are recommended due to potential negative effects on liver function and erythropoiesis. Bosentan seems to improve survival rates in children with $\mathrm{PAH}$, but the disease progression remains a concern $(55,56)$. Moreover, dosenormalized exposure in children is highly variable and differs by factor 30 (57).

A pharmacokinetic study of bosentan and tadalafil in children reported lower Tmax, T1/2 and AUC than known from adults, and found that in contrast to previous studies, bosentan trough levels were dependent on the administered dose $(39,58,59)$.

Ambrisentan is an orally administered endothelin receptor antagonist highly selective for the receptor subtype A, however, limited data are available in children (19). At present, ambrisentan use in children is considered off-label. Up to now, only one retrospective study investigating the pharmacology of ambrisentan in 38 children suggested that the use of ambrisentan may have a favorable safety profile and potential efficacy in children with $\mathrm{PAH}$, but its dosenormalized exposure is also highly variable ( factor 6) (19). Ambrisentan is administered off-label according to a weight-based dosing scheme (Table 1).

Macitentan is a dual endothelin receptor antagonist which has been approved for the treatment of PAH in adults, but is used off-label in children. Macitentan is able to penetrate deeper into the tissure and and also binds 
longer to the ETA receptor compared with bosentan (60). A single center prospective study in a cohort of 13 patients aged 12 to 35 years over 24-week showed a beneficial effect of a switch from bosentan to macitentan with respect to exercise capacity (61). After 24 weeks, there was no further increment in exercise capacity in this cohort of patients with different etiologies of PAH (62). Eighteen patients younger than 12 years were prospectively assessed after either switching from sildenafil and/or bosentan to macitentan or who were treatment-naïve (20). Schweintzger et al. reported improvements in invasive hemodynamics, tricuspid annular plane systolic excursion (TAPSE) and NT-proBNP values after median 6 months (20). Macitentan is administered to children $>12$ years of age at a dose of 5-10 $\mathrm{mg}$ daily (Table 1).

\section{Eisenmenger syndrome}

A greater survival was reported in a cohort of 253 Eisenmenger patients (66\% treated with bosentan, 35\% treated with sildenafil) despite they were comparatively sicker prior to treatment compared to untreated patients (63). The patients were followed-up for median 9 years, one third of the cohort consisted of patients with Down syndrome. A systematic review attributed bosentan a long-lasting effect on exercise tolerance in long-term treatment (44), while another review reported improved hemodynamic effects of bosentan in Eisenmenger patients, but a controversial effect on exercise capacity (64).

In the MAESTRO study in patients $>12$ years presenting with PAH-CHD and Eisenmenger syndrome, Macitentan did not show superiority over placebo on the primary end point of change from baseline to week 16 in exercise capacity (65). The investigators related this result to the inclusion of patients with Down syndrome. The patients' cooperation might not be consistent and thus 6MWD may be a less suitable endpoint, therefore the beneficial effects of $\mathrm{PAH}$-specific therapy on $6 \mathrm{MWD}$ may be less pronounced in this population (65).

\section{Fontan circulation}

Bosentan also lead to hemodynamic and functional improvement in a small series of children and adolescents with Fontan circulation and a PVR $\geq 2 \mathrm{WU}^{*} \mathrm{~m}^{2}$. They were treated with bosentan $0.5 \mathrm{mg} / \mathrm{kg}$ b.i.d., for 4 weeks, followed by $1 \mathrm{mg} / \mathrm{kg}$ b.i.d. for 5 months (maintenance period) (66). Most benefit was seen in adolescents with improved physical ability, ventilatory capacity and oxygen consumption, as well as significantly lowered pulmonary vascular resistance (PVR) and increased indexed systemic output (QSI).
Another small, placebo-controlled study of bosentan, which was dosed based on weight ranges, in pediatric Fontan patients ( $\mathrm{n}=5$ bosentan $v s . \mathrm{n}=4$ placebo) aged 6.5-13 years, found improved NYHA functional status and 6-minute walking distance while also showing a favourable side-effect profile (67).

Ambrisentan has recently been used as short-term treatment following Fontan surgery (18). Its clearance was reduced in Fontan patients aged 26-72 months; the authors suggested abnormal hepatic metabolism in this population. Furthermore, a favorable safety profile was observed and it was concluded that its hemodynamic effect may be beneficial in Fontan patients.

\section{Prostacyclin analogues and stimulators of prostacyclin receptors}

Epoprostenol was the first intravenous prostacyclin analogue used in children with PAH. Epoprostenol has no EMA approval for patients $<18$ years of age. However it has been used in several studies and has shown significant improvement of symptoms and survival (68). A disadvantage is the need for implantation of a permanent intravenous line-with associated risk of infection/sepsis and the risk of severe rebound pulmonary hypertension caused by abrupt cessation of intravenous application (e.g., when the IV catheter is clogged etc.).

Treprostinil can be given subcutaneously or intravenously. Limited data in 8 children receiving subcutaneous treprostinil have shown improvement in functional class and hemodynamics (69). Pain at the injection site represents one of the disadvantages of subcutaneous treprostinil use. Inhaled treprostinil (70) and oral treprostinil (71) have been used in small series including 32 children; all patients showed drug-related adverse events (headache, vomiting, diarrhea, flushing).

Inhaled iloprost, first reported by Olschewski and coworkers, has been used effectively in adults with PAH (72). Iloprost is not approved by the EMA for the use in children. Its use in children is limited by the patients' compliance due to the necessity of repetitive inhalations 6 times a day. Inhaled iloprost has been used in the perioperative setting in patients after intracardiac repair of left-to-right shunts (73) and children with IPAH or PAH-CHD (74).

\section{Prostacyclin receptor agonist}

Selexipag is a selective IP prostacyclin-receptor agonist. It is used in adults as an add on therapy in patients with $\mathrm{PH}$ who were treated with a dual therapy using endothelin receptor 
antagonist and phosphodiesterase-5 inhibitor therapy $(75,76)$. Selexipag reduced the risk of the primary composite endpoint of morbidity/mortality in a study in adults (77).

Limited data exist in children; no relevant side effects were reported $(78,79)$. Only recently, selexipag was used in a prospective observational study as add on therapy in 15 children with $\mathrm{PAH}$ with variable efficacy improving outcome-relevant variables in about $50 \%$ of patients (25). Another small study in 10 patients reported at least improved clinical parameters after switching from IV treprostinil to PO selexipag (80). There are no dosing recommendations for selexipag in children, but the authors used a weight-based scheme (see Table 1 for details).

\section{Direct stimulator of the soluble guanylate cyclase}

Riociguat is a direct stimulator of the soluble cGMP. In adults with CHD the PATENT-1 trial has shown its efficacy in improvement of clinical symptoms, but pediatric experience is limited (81). Current studies aim to clarify the role of riociguat in the treatment of PAH in children (24). After uptitration, the pediatric dose range is $1-2.5 \mathrm{mg}$ t.i.d. p.o. (Table 1).

\section{Early combination therapy}

Current guidelines recommend the initiation of targeted therapies based on a risk assessment (Figure 1). In children with lower risk, initiation of a PDE5 inhibitor or an ERA is recommended, whereas patients with higher risk should be treated with a combination PDE5 inhibitor + ERA upfront (+ prostacyclin, if needed) (4). Early combination therapy with two oral PAH-targeted drugs in newly diagnosed (treatment-naïve) children with $\mathrm{PAH}$ in WHO functional class II-III is reasonable $(4,7,15)$. At present, however, there is not sufficient evidence that initial combination therapy in children is superior to a mono-therapy with respect to survival, due to the lack of adequate prospective study data (for ethical reasons). A very recent retrospective study followed up on a small cohort of 21 children aged 2.512.8 years (WHO FC III/IV) who had received upfront triple therapy for up to $>6$ years (82). The patients with PAH (not PVOD) improved significantly during upfront triple combination therapy for up to 1 year, but upon last follow-up, only 7 remained on oral PAH-targeted therapy without any intervention or death. Due to the lack of a control group of similar patients with severe PAH, comparisons with an initial dual PAH-targeted drug therapy are not possible.

\section{Off label use}

There is no reason to favour the off-label drug use in children with PAH. But there is a clear need for more controlled studies of PAH combination therapy in the pediatric age group, also regarding drug-drug interactions between oral PAH-targeted drugs.

At present any medical therapy can only prolong the time until the patients' health will deteriorate. Therefore, it is mandatory to refer the patients early to a tertiary center and to discuss the option of lung transplantation before severe hemodynamic compromise will lead to clinical deterioration and medical emergencies, or even fatalities.

\section{Experimental therapeutics and novel therapeutic approaches}

\section{Ongoing studies}

Riociguat is under evaluation for treatment in children with PAH (e.g., NCT02562235) (24). Also, Selexipag is currently investigated in pediatric Phase 2 and 3 trials (NCT03492177 and NCT04175600).

\section{Novel therapies}

Several novel treatment approaches have been evaluated in adults with promising or unsatisfactory results (83). Only a limited number of these concepts can be and have been transferred to children (15). A phase 2 safety study of imatinib in children with pulmonary hypertension (NCT00583115) was terminated because of the inability to enroll subjects.

Recent studies in adults have discovered new treatment pathways (84). An overview is given in Table 2 (84-95). These concepts target inflammation, elastase inhibition, metabolic dysfunction, cellular therapies, genetic abnormalities, and DNA damage, as well as hormone treatment. Tacrolimus (FK506) has been used in adult PAH patients to enhance diminished BMPR2 signaling $(85,86)$. Tacrolimus treatment led to an increase in BMPR2 expression as well as improvement in 6-MWD, serologic and echocardiographic parameters of heart failure; but these changes were not significant in a small study of 20 patients (85).

\section{Challenges in treatment}

Giving recommendations for treatment of $\mathrm{PAH}$ in children 


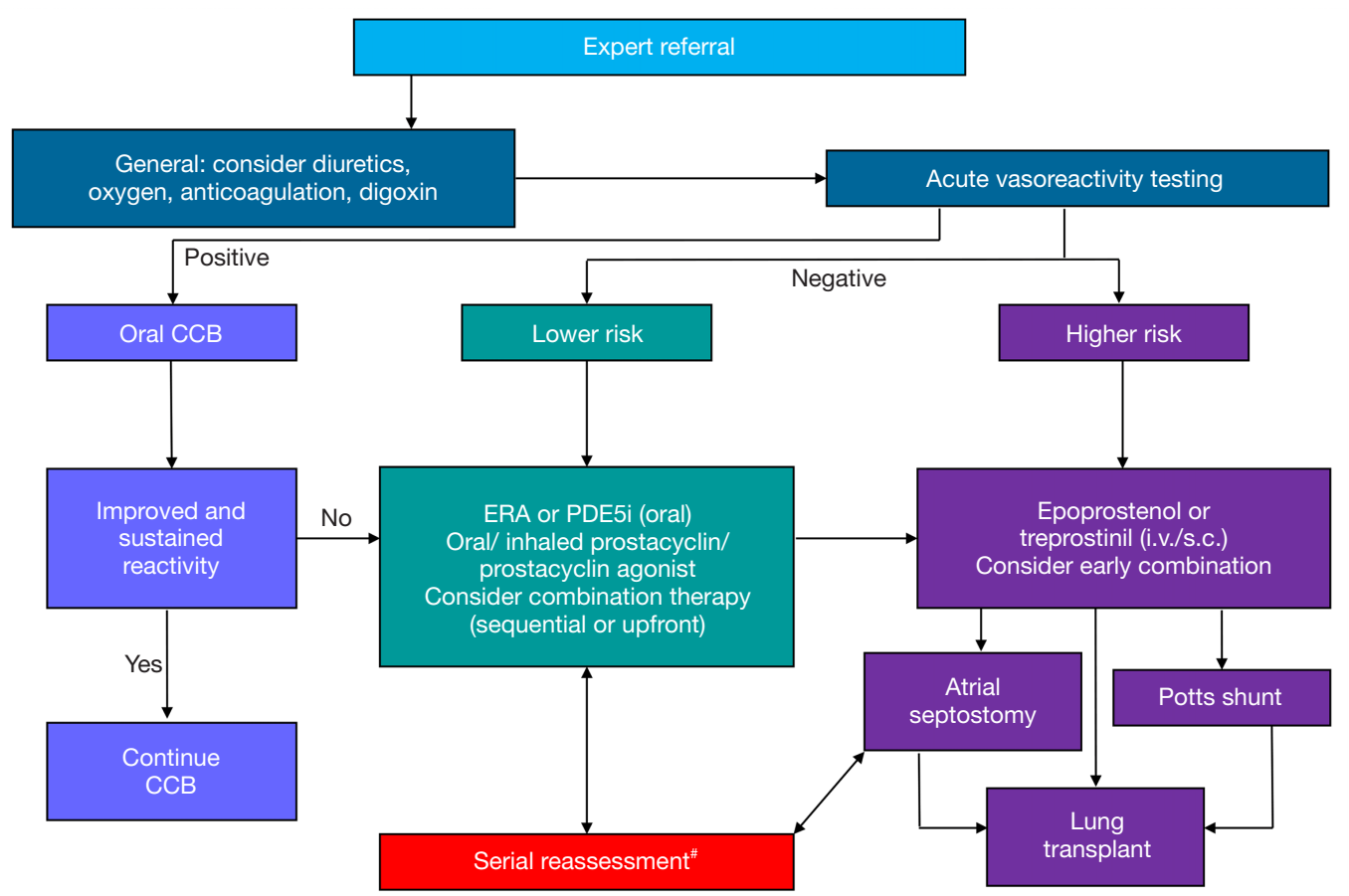

Figure 1 Pediatric idiopathic/familial pulmonary arterial hypertension treatment algorithm following current guidelines (4). *, deterioration or not meeting treatment goals. CCB, calcium channel blocker; ERA, endothelin receptor agonist; PDE5i, phosphodiesterase type 5 inhibitor.

is difficult for several reasons: (I) insufficient pediatric data available for most drugs compared to adult PAH patient cohorts; (II) variability in pharmacokinetics related to patient age and other factors (96); (III) definition of clinically suitable endpoints for the use in children $(4,15)$; (IV) evaluation and comparison of available therapies in children.

\section{Extrapolation of adult data}

Treatment algorithms have been published by European and American institutions on the basis of adult and, if available, pediatric data and consensus of experts. These algorithms mainly focus on (I) determination of risk of an individual patient and (II) the result of AVT and (III) the extent of the patient's personal impairment (Figures 1, Table 3).

The therapy of PAH in children comprises the offlabel use of drugs which are known to be effective in adults with PAH. There has a limited number of prospective studies been performed in children with PAH. Off-label prescription of pulmonary antihypertensive drugs places this vulnerable population at risk for therapeutic failures and adverse events due to insufficient knowledge about the pharmacology of these drugs in this age group.

\section{Pharmacokinetic considerations}

At present there is a lack of data with respect to pharmacokinetics and optimum dosage for most of the available drugs used in PAH treatment, their safe use and their therapeutic efficacy in children. Moreover, there are no pediatric data with respect to drug-drug interactions and side effects when using a combination of pulmonary antihypertensive drugs in infants and children.

$\mathrm{Up}$ to date, there is a lack of knowledge about the effects of a combination therapy with ERA and PDE-5 inhibitors regarding pharmacokinetic and pharmacodynamics interactions and how it influences the therapeutic outcome in pediatric PAH. When using the combination of bosentan and sildenafil it is expected that the CYP3A-mediated interaction of bosentan and sildenafil will lead to low and insufficient plasma levels of sildenafil associated with elevated plasma levels for bosentan $(16,17)$.

In a study using samples from therapeutic drug 


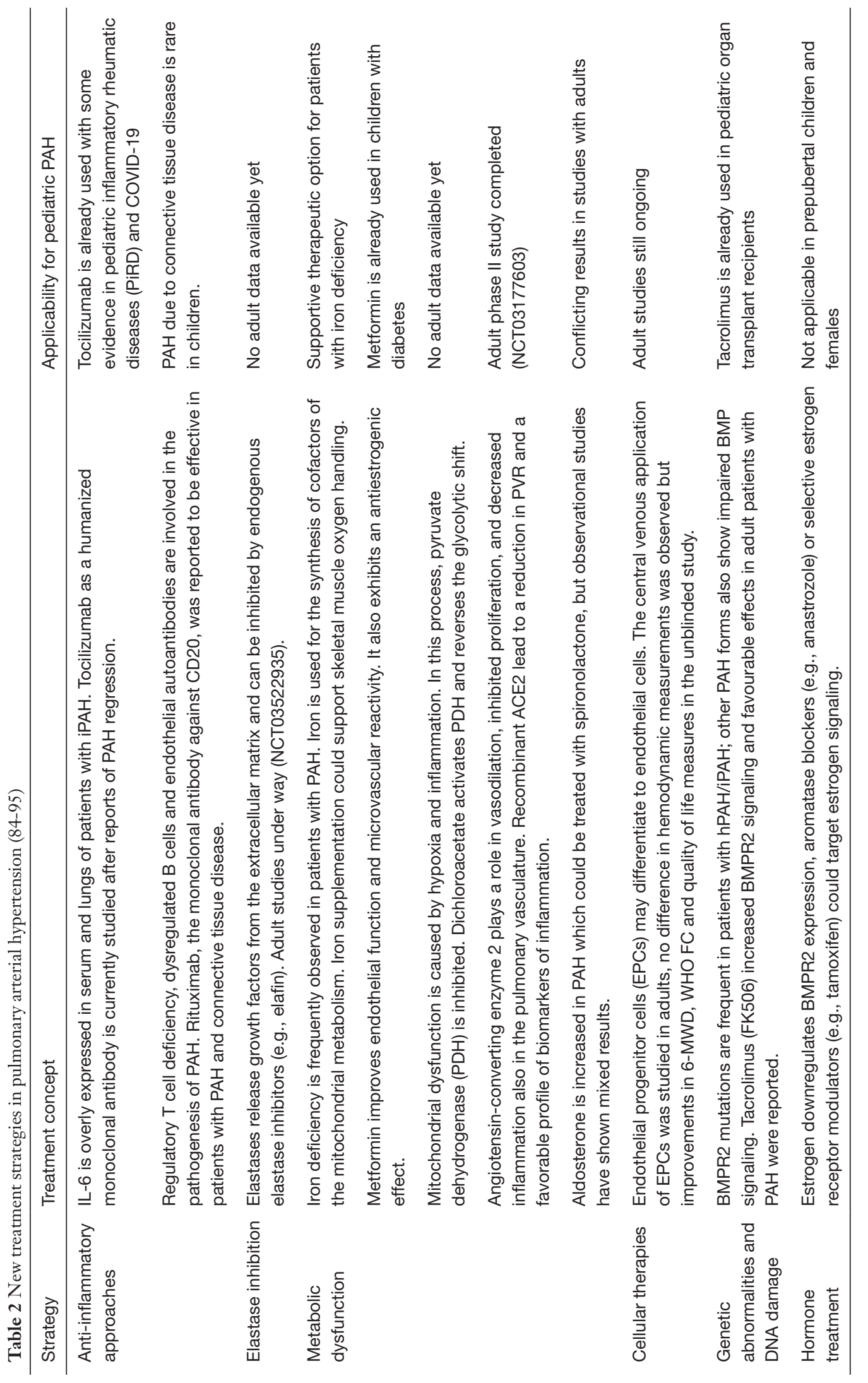


Table 3 Risk assessment in PAH (4)

\begin{tabular}{|c|c|c|}
\hline Lower risk & Determinants of risk & Higher risk \\
\hline No & Progression of symptoms & Yes \\
\hline$>350$ & $6 \mathrm{MWT}$ (>6 years old) $\mathrm{m}$ & $<350$ \\
\hline Normal & Growth & Failure to thrive \\
\hline \multirow[t]{6}{*}{ Minimally elevated } & Serum BNP/NT-proBNP & RA/RV enlargement \\
\hline & & Rising level \\
\hline & Echocardiography & RA/RV enlargement \\
\hline & & Reduced LV size \\
\hline & & Low RV FAC \\
\hline & & Pericardial effusion \\
\hline Systemic $\mathrm{Cl}>3.0 \mathrm{~L} / \mathrm{min} / \mathrm{m}^{2}$ & Haemodynamics & Systemic $\mathrm{Cl}<2.5 \mathrm{~L} / \mathrm{min} / \mathrm{m}^{2}$ \\
\hline Systemic venous saturation $>65 \%$ & & mRAP >10 mmHg \\
\hline \multirow[t]{3}{*}{ Acute vasoreactivity } & & $\mathrm{PVRI}>20 \mathrm{WU} / \mathrm{m}^{2}$ \\
\hline & & Systemic venous saturation $<60 \%$ \\
\hline & & $\mathrm{PACl}<0.85 \mathrm{~mL} / \mathrm{mmHg} / \mathrm{m}^{2}$ \\
\hline
\end{tabular}

RV, right ventricle; 6MWT, 6-min walk test; WHO, World Health Organization; FC, Functional Class; BNP, brain natriuretic peptide; NT-proBNP, N-terminal pro-BNP; RA, right atrium; LV, left ventricle; FAC, fractional area change; TAPSE, tricuspid annular plane systolic excursion; $\mathrm{Cl}$, cardiac index; mRAP, mean right atrial pressure; PVRI, pulmonary vascular resistance index; WU, Wood Units; PACI, pulmonary arterial compliance index.

monitoring in adults, sildenafil or tadalafil concentrations were lowest in combination with bosentan compared to the combinations with ambrisentan and macitentan (17). The combination of sildenafil and bosentan led to more than twice the expected bosentan concentrations in 53.8\% of patients. Patients switching from sildenafil-bosentan to macitentan showed a significant increase in sildenafil concentrations. It was concluded that bosentan and sildenafil showed the most pronounced interaction. In contrast, Nakau et al. reported significantly higher blood tadalafil concentrations in pediatric patients who received concomitant bosentan and prostacyclin (39).

With respect to the bioavailability of sildenafil the limited resorption in small children has to be taken into account and sublingual administration may be preferred $(35,36)$. Preliminary data indicate a reduced enteral absorption of orally administered sildenafil in infants and children resulting in a decreased oral bioavailability of this drug $(34,35)$. Data collected through therapeutic drug monitoring (TDM) in critically ill children with PAH admitted to ICU in our hospital showed that $75 \%$ of the patients did not reach therapeutic plasma levels of sildenafil (96). A possible explanation for the variable enteral absorption might be a compromised intestinal blood flow due to heart failure emphasizing the need for alternative routes of administration. TDM data obtained for ambrisentan showed a higher clearance in pediatric intensive care patients.

Other factors modulating the pharmacology of these drugs are genetic polymorphisms of drug transporters, drug metabolizing enzymes and receptors which can influence drug disposition as well as efficacy and safety of the therapy. The impact of ontogeny, the process of 
growth and maturation, may affect pharmacokinetics (97). For example, infants and younger children may show a higher metabolic activity than adults leading to an increased clearance capacity and insufficient exposure to the particular drug. Therapeutic drug monitoring should thus be applied in pediatric patients with insufficient therapeutic response $(36,39)$.

Due to the devastating prognosis of $\mathrm{PAH}$ in children, it is crucial to investigate the pharmacology of orally administered pulmonary antihypertensive drugs like ERA and PDE-5 inhibitors in children in order to optimize their pharmacological treatment with focus on survival and quality of life.

\section{Optimal endpoints for pediatric PAH}

In pediatric $\mathrm{PAH}$, there are unique challenges to drug development and evaluation, including identifying appropriate study endpoints, enrolling patients, and conducting randomized, controlled, double-blind clinical studies in which the likelihood of meeting the study endpoint is optimized.

For pediatric $\mathrm{PAH}$ trials, clinically meaningful endpoints should be used, and due to the wide age span and underlying diagnoses, composite endpoints should be used in children, e.g., combinations of (98): (I) clinical events relevant to the patient, such as death, transplant, hospitalisation for $\mathrm{PAH}$ and (II) direct assessments how a patient feels, functions, or survives: symptoms, functional class, exercise testing, $6 M W D$, activities of daily life.

In order to "normalize" assessment conditions for the patients, actigraphy could be used to record activity during the daily-life routine (99).

Awerbach et al. described the characteristics of pediatric pulmonary hypertension trials registered on ClinicalTrials. gov over a period of $\sim 10$ years (100). They found 45 registered pediatric $\mathrm{PH}$ trials, $50 \%$ were industrysponsored. The authors reported varying study outcomes with inconsistent use of known surrogate and composite endpoints. Phosphodiesterase inhibitors (39\%) were the most frequently studied drugs. One-third of the listed trials were terminated, predominantly due to poor participant enrollment. Of the 17 completed trials, only three efficacy trials met their primary endpoint.

Beghetti et al. also discuss the challenges of studies in pediatric PAH (101), especially age-appropriate evaluation and endpoints. Patient registries could support trial development by finding the optimal endpoints.

For the evaluation and comparability of therapies, especially for a rare disease like PAH in children, it is essential to track the patients' clinical course and therapy. Up to now, more than 3,000 children worldwide have been included in therapeutic registries, such as PPHnet (North America), TOPP 1 and 2 registry (international) (102), REVEAL pediatric, COMPERA-Kids (international), and the Spanish PAH registry. Through pooling of data across registries and clinical trials, $\mathrm{PAH}$ therapy in children should be standardized and optimized (24).

\section{Conclusions}

At present, pediatric PAH is still a life-threatening disease. But PAH treatment has advanced significantly over the past decade through the continous reevaluation of treatment guidelines. New targeted therapies are currently evaluated regarding their efficacy and safety in children, in order to limit off-label use. Due to the different etiologies, such as $\mathrm{PAH}-\mathrm{CHD}$ and $\mathrm{PAH} / \mathrm{hPAH}$, in children, there is no evidence that initial combination therapy in children is superior to a mono-therapy with respect to survival. There is a clear need for more controlled studies of PAH medications, alone or in combination therapy in the pediatric age group.

\section{Acknowledgments}

Figures 1,2 were reproduced with permission of the ERS $2020^{\odot}$ : European Respiratory Journal.

Funding: None.

\section{Footnote}

Provenance and Peer Review: This article was commissioned by the Guest Editors (Christian Apitz and Astrid Lammers) for the series "Pediatric Pulmonary Hypertension" published in Cardiovascular Diagnosis and Therapy. The article has undergone external peer review.

Conflicts of Interest: Both authors have completed the ICMJE uniform disclosure form (available at http://dx.doi. org/10.21037/cdt-20-912). The series "Pediatric Pulmonary Hypertension" was commissioned by the editorial office without any funding or sponsorship. MG reports personal fees from Actelion, personal fees from MSD, personal fees 
from Pfizer, personal fees from Bayer, outside the submitted work. The authors have no other conflicts of interest to declare.

Ethical Statement: The authors are accountable for all aspects of the work in ensuring that questions related to the accuracy or integrity of any part of the work are appropriately investigated and resolved.

Open Access Statement: This is an Open Access article distributed in accordance with the Creative Commons Attribution-NonCommercial-NoDerivs 4.0 International License (CC BY-NC-ND 4.0), which permits the noncommercial replication and distribution of the article with the strict proviso that no changes or edits are made and the original work is properly cited (including links to both the formal publication through the relevant DOI and the license). See: https://creativecommons.org/licenses/by-nc-nd/4.0/.

\section{References}

1. Simonneau G, Robbins IM, Beghetti M, et al. Updated clinical classification of pulmonary hypertension. J Am Coll Cardiol 2009;54:S43-54.

2. van Loon RL, Roofthooft MT, Hillege HL, et al. Pediatric pulmonary hypertension in the Netherlands: epidemiology and characterization during the period 1991 to 2005. Circulation 2011;124:1755-64.

3. Galiè N, Hoeper MM, Humbert M, et al. Guidelines for the diagnosis and treatment of pulmonary hypertension: the Task Force for the Diagnosis and Treatment of Pulmonary Hypertension of the European Society of Cardiology (ESC) and the European Respiratory Society (ERS), endorsed by the International Society of Heart and Lung Transplantation (ISHLT). Eur Heart J 2009;30:2493-537.

4. Rosenzweig EB, Abman SH, Adatia I, et al. Paediatric pulmonary arterial hypertension: updates on definition, classification, diagnostics and management. Eur Respir J 2019;53:1801916.

5. Rich S, Kaufmann E, Levy PS. The effect of high doses of calcium-channel blockers on survival in primary pulmonary hypertension. N Engl J Med 1992;327:76-81.

6. Pelland-Marcotte MC, Humpl T, James PD, et al. Idiopathic pulmonary arterial hypertension - a unrecognized cause of high-shear high-flow haemostatic defects (otherwise referred to as acquired von Willebrand syndrome) in children. Br J Haematol 2018;183:267-75.
7. Hansmann G, Koestenberger M, Alastalo TP, et al. 2019 updated consensus statement on the diagnosis and treatment of pediatric pulmonary hypertension: The European Pediatric Pulmonary Vascular Disease Network (EPPVDN), endorsed by AEPC, ESPR and ISHLT. J Heart Lung Transplant 2019;38:879-901.

8. Olschewski H, Rich S. Are anticoagulants still indicated in pulmonary arterial hypertension? Pulm Circ 2018;8:2045894018807681.

9. Male C, Thom K, O'Brien SH. Direct oral anticoagulants: What will be their role in children? Thromb Res 2019;173:178-85.

10. Halton JM, Lehr T, Cronin L, et al. Safety, tolerability and clinical pharmacology of dabigatran etexilate in adolescents. An open-label phase IIa study. Thromb Haemost 2016;116:461-71.

11. Halton JML, Albisetti M, Biss B, et al. Phase IIa study of dabigatran etexilate in children with venous thrombosis: pharmacokinetics, safety, and tolerability. J Thromb Haemost 2017;15:2147-57.

12. Margelidon-Cozzolino V, Hodin S, Jacqueroux E, et al. In Vitro Assessment of Pharmacokinetic DrugDrug Interactions of Direct Oral Anticoagulants: Type 5-Phosphodiesterase Inhibitors Are Inhibitors of Rivaroxaban and Apixaban Efflux by P-Glycoprotein. J Pharmacol Exp Ther 2018;365:519-25.

13. Abman SH, Hansmann G, Archer SL, et al. Pediatric Pulmonary Hypertension: Guidelines From the American Heart Association and American Thoracic Society. Circulation 2015;132:2037-99.

14. Sitbon O, Humbert M, Jais X, et al. Long-term response to calcium channel blockers in idiopathic pulmonary arterial hypertension. Circulation 2005;111:3105-11.

15. Avitabile CM, Vorhies EE, Ivy DD. Drug Treatment of Pulmonary Hypertension in Children. Paediatr Drugs 2020;22:123-47.

16. Apitz C, Schranz D. Sildenafil-Bosentan Drug-Drug Interaction: A Word of Caution Regarding the Most Common Combination Therapy in Children with Advanced Pulmonary Arterial Hypertension. Respiration 2018;96:302.

17. Grünig E, Ohnesorge J, Benjamin N, et al. Plasma Drug Concentrations in Patients with Pulmonary Arterial Hypertension on Combination Treatment. Respiration 2017;94:26-37.

18. Hill KD, Maharaj AR, Li JS, et al. A Randomized, Controlled Pharmacokinetic and Pharmacodynamics Trial of Ambrisentan After Fontan Surgery. Pediatr Crit Care 
Med 2020;21:e795-803.

19. Takatsuki S, Rosenzweig EB, Zuckerman W, et al. Clinical safety, pharmacokinetics, and efficacy of ambrisentan therapy in children with pulmonary arterial hypertension. Pediatr Pulmonol 2013;48:27-34.

20. Schweintzger S, Koestenberger M, Schlagenhauf A, et al. Safety and efficacy of the endothelin receptor antagonist macitentan in pediatric pulmonary hypertension. Cardiovasc Diagn Ther 2020;10:1675-85.

21. Barst RJ, Ivy DD, Gaitan G, et al. A randomized, double-blind, placebo-controlled, dose-ranging study of oral sildenafil citrate in treatment-naive children with pulmonary arterial hypertension. Circulation 2012;125:324-34.

22. Barst RJ, Beghetti M, Pulido T, et al. STARTS-2: long-term survival with oral sildenafil monotherapy in treatment-naive pediatric pulmonary arterial hypertension. Circulation 2014;129:1914-23.

23. Sabri MR, Beheshtian E. Comparison of the therapeutic and side effects of tadalafil and sildenafil in children and adolescents with pulmonary arterial hypertension. Pediatr Cardiol 2014;35:699-704.

24. Beghetti M, Gorenflo M, Ivy DD, et al. Treatment of pediatric pulmonary arterial hypertension: A focus on the NO-sGC-cGMP pathway. Pediatr Pulmonol 2019;54:1516-26.

25. Hansmann G, Meinel K, Bukova M, et al. Selexipag for the treatment of children with pulmonary arterial hypertension: First multicenter experience in drug safety and efficacy. J Heart Lung Transplant 2020;39:695-706.

26. Barst RJ, Maislin G, Fishman AP. Vasodilator therapy for primary pulmonary hypertension in children. Circulation 1999; 99:1197-208.

27. Tissot C, Ivy DD, Beghetti M. Medical therapy for pediatric pulmonary arterial hypertension. J Pediatr 2010;157:528-32.

28. Oishi P, Datar SA, Fineman JR. Advances in the management of pediatric pulmonary hypertension. Respir Care 2011;56:1314-39; discussion 1339-40.

29. Karatza AA, Bush A, Magee AG. Safety and efficacy of Sildenafil therapy in children with pulmonary hypertension. Int J Cardiol 2005;100:267-73.

30. Dhariwal AK, Bavdekar SB. Sildenafil in pediatric pulmonary arterial hypertension. J Postgrad Med 2015;61:181-92.

31. Simonca L, Tulloh R. Sildenafil in Infants and Children. Children (Basel) 2017;4:60.

32. Cohen JL, Nees SN, Valencia GA, et al. Sildenafil Use in Children with Pulmonary Hypertension. J Pediatr 2019;205:29-34.e1.

33. Mourani PM, Sontag MK, Ivy DD, et al. Effects of longterm sildenafil treatment for pulmonary hypertension in infants with chronic lung disease. J Pediatr 2009;154:37984, 84.e1-2.

34. Apitz C, Reyes JT, Holtby H, et al. Pharmacokinetic and hemodynamic responses to oral sildenafil during invasive testing in children with pulmonary hypertension. J Am Coll Cardiol 2010;5 5:1456-62.

35. Ahsman MJ, Witjes BC, Wildschut ED, et al. Sildenafil exposure in neonates with pulmonary hypertension after administration via a nasogastric tube. Arch Dis Child Fetal Neonatal Ed 2010;95:F109-14.

36. Carls A, Winter J, Enderle Y, et al. Substantially increased sildenafil bioavailability after sublingual administration in children with congenital heart disease: two case reports. J Med Case Rep 2014;8:171.

37. Takahiro R, Nakamura S, Kohno H, et al. Contribution of CYP3A isoforms to dealkylation of PDE5 inhibitors: a comparison between sildenafil $\mathrm{N}$-demethylation and tadalafil demethylenation. Biol Pharm Bull 2015;38:58-65.

38. Kohno H, Ichida F, Hirono K, et al. Plasma concentrations of tadalafil in children with pulmonary arterial hypertension. Ther Drug Monit 2014;36:576-83.

39. Nakau K, Sugimoto M, Oka H, et al. Pharmacokinetics of drugs for pediatric pulmonary hypertension. Pediatr Int 2016;58:1112-7.

40. Takatsuki S, Calderbank M, Ivy DD. Initial experience with tadalafil in pediatric pulmonary arterial hypertension. Pediatr Cardiol 2012;33:683-8.

41. Shiva A, Shiran M, Rafati M, et al. Oral Tadalafil in Children with Pulmonary Arterial Hypertension. Drug Res (Stuttg) 2016;66:7-10.

42. Yamazaki H, Kobayashi N, Taketsuna M, et al. Safety and effectiveness of tadalafil in pediatric patients with pulmonary arterial hypertension: a sub-group analysis based on Japan post-marketing surveillance. Curr Med Res Opin 2017;33:2241-9.

43. Sabri MR, Bigdelian H, Hosseinzadeh M, et al. Comparison of the therapeutic effects and side effects of tadalafil and sildenafil after surgery in young infants with pulmonary arterial hypertension due to systemic-topulmonary shunts. Cardiol Young 2017;27:1686-93.

44. Li Q, Kuang HY, Wu YH, et al. What is the position of pulmonary arterial hypertension-specific drug therapy in patients with Eisenmenger syndrome: A systematic review and meta-analysis. Medicine (Baltimore) 2019;98:e15632. 
45. Tay EL, Papaphylactou M, Diller GP, et al. Quality of life and functional capacity can be improved in patients with Eisenmenger syndrome with oral sildenafil therapy. Int J Cardiol 2011;149:372-6.

46. Sun YJ, Yang T, Zeng WJ, et al. Impact of sildenafil on survival of patients with Eisenmenger syndrome. J Clin Pharmacol 2013;53:611-8.

47. Raposo-Sonnenfeld I, Otero-Gonzalez I, Blanco-Aparicio $\mathrm{M}$, et al. Treatment with sildenafil, bosentan, or both in children and young people with idiopathic pulmonary arterial hypertension and Eisenmenger's syndrome. Rev Esp Cardiol 2007;60:366-72.

48. Bharani A, Patel A, Saraf J, et al. Efficacy and safety of PDE-5 inhibitor tadalafil in pulmonary arterial hypertension. Indian Heart J 2007;59:323-8.

49. Mukhopadhyay S, Nathani S, Yusuf J, et al. Clinical efficacy of phosphodiesterase-5 inhibitor tadalafil in Eisenmenger syndrome--a randomized, placebocontrolled, double-blind crossover study. Congenit Heart Dis 2011;6:424-31.

50. Tunks RD, Barker PC, Benjamin DK, Jr., et al. Sildenafil exposure and hemodynamic effect after Fontan surgery. Pediatr Crit Care Med 2014;15:28-34.

51. Mori H, Park IS, Yamagishi H, et al. Sildenafil reduces pulmonary vascular resistance in single ventricular physiology. Int J Cardiol 2016;221:122-7.

52. Hager A, Weber R, Muller J, et al. Predictors of sildenafil effects on exercise capacity in adolescents and adults with Fontan circulation. Clin Res Cardiol 2014;103:641-6.

53. Oldenburger NJ, Mank A, Etnel J, et al. Drug therapy in the prevention of failure of the Fontan circulation: a systematic review. Cardiol Young 2016;26:842-50.

54. Sabri MR, Zolfi-Gol A, Ahmadi A, et al. Effect of Tadalafil on Myocardial and Endothelial Function and Exercise Performance After Modified Fontan Operation. Pediatr Cardiol 2016;37:55-61.

55. Ivy DD, Rosenzweig EB, Lemarie JC, et al. Long-term outcomes in children with pulmonary arterial hypertension treated with bosentan in real-world clinical settings. Am J Cardiol 2010;106:1332-8.

56. Beghetti M, Hoeper MM, Kiely DG, et al. Safety experience with bosentan in 146 children 2-11 years old with pulmonary arterial hypertension: results from the European Postmarketing Surveillance program. Pediatr Res 2008;64:200-4.

57. Taguchi M, Ichida F, Hirono K, et al. Pharmacokinetics of bosentan in routinely treated Japanese pediatric patients with pulmonary arterial hypertension. Drug Metab
Pharmacokinet 2011;26:280-7.

58. Beghetti M, Haworth SG, Bonnet D, et al.

Pharmacokinetic and clinical profile of a novel formulation of bosentan in children with pulmonary arterial hypertension: the FUTURE-1 study. Br J Clin Pharmacol 2009;68:948-55.

59. Weber C, Schmitt R, Birnboeck H, et al. Multiple-dose pharmacokinetics, safety, and tolerability of bosentan, an endothelin receptor antagonist, in healthy male volunteers. J Clin Pharmacol 1999;39:703-14.

60. Belge C, Delcroix M. Treatment of pulmonary arterial hypertension with the dual endothelin receptor antagonist macitentan: clinical evidence and experience. Ther Adv Respir Dis 2019;13:1753466618823440.

61. Aypar E, Alehan D, Karagoz T, et al. Clinical efficacy and safety of switch from bosentan to macitentan in children and young adults with pulmonary arterial hypertension. Cardiol Young 2018;28:542-7.

62. Aypar E, Alehan D, Karagoz T, et al. Clinical efficacy and safety of switch from bosentan to macitentan in children and young adults with pulmonary arterial hypertension: extended study results. Cardiol Young 2020;30:681-5.

63. Arnott C, Strange G, Bullock A, et al. Pulmonary vasodilator therapy is associated with greater survival in Eisenmenger syndrome. Heart 2017. doi: 10.1136/ heartjnl-2017-311876.

64. Elshafay A, Truong DH, AboElnas MM, et al. The Effect of Endothelin Receptor Antagonists in Patients with Eisenmenger Syndrome: A Systematic Review. Am J Cardiovasc Drugs 2018;18:93-102.

65. Gatzoulis MA, Landzberg M, Beghetti M, et al. Evaluation of Macitentan in Patients With Eisenmenger Syndrome. Circulation 2019;139:51-63.

66. Agnoletti G, Gala S, Ferroni F, et al. Endothelin inhibitors lower pulmonary vascular resistance and improve functional capacity in patients with Fontan circulation. J Thorac Cardiovasc Surg 2017;153:1468-75.

67. Shang XK, Lu R, Zhang X, et al. Efficacy of Bosentan in patients after Fontan procedures: a double-blind, randomized controlled trial. J Huazhong Univ Sci Technolog Med Sci 2016;36:534-40.

68. Lammers AE, Hislop AA, Flynn Y, et al. Epoprostenol treatment in children with severe pulmonary hypertension. Heart 2007;93:739-43.

69. Levy M, Celermajer DS, Bourges-Petit E, et al. Add-on therapy with subcutaneous treprostinil for refractory pediatric pulmonary hypertension. J Pediatr 2011;158:584-8.

70. McLaughlin VV, Benza RL, Rubin LJ, et al. Addition of 
inhaled treprostinil to oral therapy for pulmonary arterial hypertension: a randomized controlled clinical trial. J Am Coll Cardiol 2010;55:1915-22.

71. Ivy DD, Feinstein JA, Yung D, et al. Oral treprostinil in transition or as add-on therapy in pediatric pulmonary arterial hypertension. Pulm Circ 2019;9:2045894019856471.

72. Olschewski H, Hoeper MM, Behr J, et al. Long-term therapy with inhaled iloprost in patients with pulmonary hypertension. Respir Med 2010;104:731-40.

73. Loukanov T, Bucsenez D, Springer W, et al. Comparison of inhaled nitric oxide with aerosolized iloprost for treatment of pulmonary hypertension in children after cardiopulmonary bypass surgery. Clin Res Cardiol 2011;100:595-602.

74. Ivy DD, Doran AK, Smith KJ, et al. Short- and longterm effects of inhaled iloprost therapy in children with pulmonary arterial hypertension. J Am Coll Cardiol 2008;51:161-9.

75. Ghosh RK, Ball S, Das A, et al. Selexipag in Pulmonary Arterial Hypertension: Most Updated Evidence From Recent Preclinical and Clinical Studies. J Clin Pharmacol 2017;57:547-57.

76. Sitbon O, Channick R, Chin KM, et al. Selexipag for the Treatment of Pulmonary Arterial Hypertension. N Engl J Med 2015;373:2522-33.

77. Coghlan JG, Channick R, Chin K, et al. Targeting the Prostacyclin Pathway with Selexipag in Patients with Pulmonary Arterial Hypertension Receiving Double Combination Therapy: Insights from the Randomized Controlled GRIPHON Study. Am J Cardiovasc Drugs 2018;18:37-47.

78. Rothman A, Cruz G, Evans WN, et al. Hemodynamic and clinical effects of selexipag in children with pulmonary hypertension. Pulm Circ 2020;10:2045894019876545.

79. Geerdink LM, Bertram H, Hansmann G. First-in-child use of the oral selective prostacyclin IP receptor agonist selexipag in pulmonary arterial hypertension. Pulm Circ 2017;7:551-4.

80. Gallotti R, Drogalis-Kim DE, Satou G, et al. SingleCenter Experience Using Selexipag in a Pediatric Population. Pediatr Cardiol 2017;38:1405-9.

81. Spreemann T, Bertram H, Happel CM, et al. First-inchild use of the oral soluble guanylate cyclase stimulator riociguat in pulmonary arterial hypertension. Pulm Circ 2018;8:2045893217743123.

82. Haarman MG, Levy M, Roofthooft MTR, et al. Upfront triple combination therapy in severe paediatric pulmonary arterial hypertension. Eur Respir J 2021;57:2001120.

83. Goldberg AB, Mazur W, Kalra DK. Pulmonary hypertension: diagnosis, imaging techniques, and novel therapies. Cardiovasc Diagn Ther 2017;7:405-17.

84. Spiekerkoetter E, Kawut SM, de Jesus Perez VA. New and Emerging Therapies for Pulmonary Arterial Hypertension. Annu Rev Med 2019;70:45-59.

85. Spiekerkoetter E, Sung YK, Sudheendra D, et al. Randomised placebo-controlled safety and tolerability trial of FK506 (tacrolimus) for pulmonary arterial hypertension. Eur Respir J 2017;50:1602449.

86. Spiekerkoetter E, Tian X, Cai J, et al. FK506 activates BMPR2, rescues endothelial dysfunction, and reverses pulmonary hypertension. J Clin Invest 2013;123:3600-13.

87. Kawut SM, Archer-Chicko CL, DeMichele A, et al. Anastrozole in Pulmonary Arterial Hypertension. A Randomized, Double-Blind, Placebo-controlled Trial. Am J Respir Crit Care Med 2017;195:360-8.

88. Kaushik S, Aydin SI, Derespina KR, et al. Multisystem Inflammatory Syndrome in Children Associated with Severe Acute Respiratory Syndrome Coronavirus 2 Infection (MIS-C): A Multi-institutional Study from New York City. J Pediatr 2020;224:24-9.

89. Machado SH, Xavier RM. Safety of tocilizumab in the treatment of juvenile idiopathic arthritis. Expert Opin Drug Saf 2017;16:493-500.

90. Fernández-Codina A, Walker KM, Pope JE, et al. Treatment Algorithms for Systemic Sclerosis According to Experts. Arthritis Rheumatol 2018;70:1820-8.

91. Ruiter G, Manders E, Happe CM, et al. Intravenous iron therapy in patients with idiopathic pulmonary arterial hypertension and iron deficiency. Pulm Circ 2015;5: 466-72.

92. Hernández-Sánchez J, Harlow L, Church C, et al. Clinical trial protocol for TRANSFORM-UK: A therapeutic open-label study of tocilizumab in the treatment of pulmonary arterial hypertension. Pulm Circ 2018;8:2045893217735820.

93. Spiekerkoetter E, Sung YK, Sudheendra D, et al. LowDose FK506 (Tacrolimus) in End-Stage Pulmonary Arterial Hypertension. Am J Respir Crit Care Med 2015;192:254-7.

94. Granton J, Langleben D, Kutryk MB, et al. Endothelial NO-Synthase Gene-Enhanced Progenitor Cell Therapy for Pulmonary Arterial Hypertension: The PHACe'T Trial. Circ Res 2015;117:645-54.

95. Hemnes AR, Rathinasabapathy A, Austin EA, et al. A potential therapeutic role for angiotensin-converting 
enzyme 2 in human pulmonary arterial hypertension. Eur Respir J 2018;51:1702638.

96. Ziesenitz V, Grommes S, Burhenne J, et al. Sildenafil Plasma Concentrations during Routine Treatment of Children with Pulmonary Arterial Hypertension. Cardiol Young 2018;28:S148.

97. van den Anker JN, Schwab M, Kearns GL. Developmental pharmacokinetics. Handb Exp Pharmacol 2011;205:51-75.

98. Beghetti M, Brand M, Berger RMF, et al. Meaningful and feasible composite clinical worsening definitions in paediatric pulmonary arterial hypertension: An analysis of the TOPP registry. Int J Cardiol 2019;289:110-5.

99. Sehgal S, Chowdhury A, Rabih F, et al. Counting Steps:

Cite this article as: Gorenflo M, Ziesenitz VC. Treatment of pulmonary arterial hypertension in children. Cardiovasc Diagn Ther 2021;11(4):1144-1159. doi: 10.21037/cdt-20-912
A New Way to Monitor Patients with Pulmonary Arterial Hypertension. Lung 2019;197:501-8.

100. Awerbach JD, Krasuski RA, Hill KD. Characteristics of pediatric pulmonary hypertension trials registered on ClinicalTrials.gov. Pulm Circ 2017;7:348-60.

101. Beghetti M, Berger RM. The challenges in paediatric pulmonary arterial hypertension. Eur Respir Rev 2014;23:498-504.

102.Humpl T, Berger RMF, Austin ED, et al. Treatment initiation in paediatric pulmonary hypertension: insights from a multinational registry. Cardiol Young 2017;27:1123-32. 